\title{
A Major Gene for Resistance to White Pine Blister Rust in Western White Pine from the Western Cascade Range
}

\author{
Bohun B. Kinloch, Jr., Richard A. Sniezko, Gerald D. Barnes, and Tom E. Greathouse
}

First author: USDA Forest Service, Institute of Forest Genetics, Box 245, Berkeley, CA 94701; second author: USDA Forest Service, Dorena Genetic Resource Center, Cottage Grove, OR 97424; third author: Tree Improvement Enterprises, Cottage Grove, OR 97424; and fourth author: Box 392, Newcastle, New Brunswick, Canada E1V 3M5. Accepted for publication 9 June 1999.

\begin{abstract}
Kinloch, Jr., B. B., Sniezko, R. A., Barnes, G. D., and Greathouse, T. E. 1999. A major gene for resistance to white pine blister rust in western white pine from the Western Cascade Range. Phytopathology 89:861-867.

A dominant gene for resistance to white pine blister was indicated by Mendelian segregation in full-sib families of western white pine parent trees selected for phenotypic resistance in six heavily infected stands in the Western Cascades of Oregon and Washington. Seedlings were artificially inoculated three times between 1959 and 1964 and observed for development of stem infection. Segregation at this locus $(\mathrm{Cr} 2)$ occurred in only two of the six parent populations sampled: one a natural stand, Champion Mine (CM), and the other a plantation of unknown seed origin. At $\mathrm{CM}$, reduced penetrance of this gene was expressed by altered Mendelian ratios (mostly less-than-expected resistant phenotypes) in families of specific combinations of certain parents, indicating the presence of modifier genes with effects that ranged from mild to almost complete suppres-
\end{abstract}

ABSTRACT sion of Cr2. Between 1968 and 1994, an apparent shift in virulence at CM caused all of the resistant selections to become infected and die. Recent inoculations of many of the same or related families from these parents, made from grafted ramets in a seed orchard, showed that $\mathrm{Cr} 2$ conditions a classical hypersensitive reaction (HR) in needle tissues, the primary infection courts. In the latter tests, seedlings were challenged with wild-type and four other sources of inoculum at and near CM that were also suspected of having wider virulence than wild type. No seedlings segregating for HR that were inoculated with wild type subsequently developed stem symptoms, but the other inocula induced both susceptible and HR needle spots on Cr2- genotypes, and many of these seedlings did develop stem infections. This implied that spore genotypes with specific virulence to $\mathrm{Cr} 2$ are carried in these inocula.

Additional keywords: Cronartium ribicola, genetic background, hypersensitivity, Pinus monticola.
Western white pine (Pinus monticola Douglas) has historically been one of the most valuable conifers in western North America, both economically and ecologically. It has the potential to grow to great size and stand densities, producing large amounts of clear wood of unsurpassed quality. A seral species at middle and upper elevations, it ranges widely in the western cordillera of Canada and the United States (4). Its relative resistance or tolerance to several native root pathogens allows it to dominate many sites where more shade-tolerant climax species would dominate in the absence of these pathogens (5). But after the introduction of white pine blister rust (caused by Cronartium ribicola J.C. Fisch.) almost a century ago, many populations of this and other white pine species have been severely damaged. In the northern Rocky Mountains, for example, up to $95 \%$ of the once nearly pure stands of white pine have been destroyed (15). The disease kills seedlings and saplings directly and large trees indirectly by damaging their crowns so badly that they become stressed and predisposed to bark beetles. Most importantly, regeneration is severely limited in areas of high rust hazard, altering patterns of succession. After the abandonment of massive programs to eradicate alternate hosts (1) or to control the disease directly by antibiotic sprays (17), genetic resistance came to be considered the most feasible and effective method of control.

In the late 1950s, the U.S. Forest Service, Pacific Northwest Region, began a tree improvement program to select, breed, and test

Corresponding author: B. B. Kinloch, Jr.; E-mail address: bkinloch/psw@fs.fed.us

Publication no. P-1999-0820-02R

This article is in the public domain and not copyrightable. It may be freely reprinted with customary crediting of the source. The American Phytopathological Society, 1999. candidate western white pine parent trees for resistance to blister rust for the Cascade and Coast Ranges of Oregon and Washington. The program was developmental, modeled on earlier research by R. T. Bingham (2) and associates at Moscow, ID, for the blister rust problem in the northern Rocky Mountains. The early results from artificial inoculations, recorded, filed, and summarized in internal office memoranda, strongly suggested that a qualitative resistance existed in a significant number of full-sib families from phenotypically resistant parents. This was surprising at the time, since resistance to blister rust was thought to be entirely quantitative (3). Other ambiguities remained: parents in only two of the six populations sampled expressed this kind of resistance; but in both of these, the frequencies were so high the data were considered suspect. Also, progenies of certain of these parent trees did not perform consistently in different crosses. Furthermore, in subsequent years, the apparent resistance evident earlier was seen to erode or become erratic in expression. New infections started to be observed even in some of the originally resistant parent selections in one of the stands around 1970, and within 2 decades, all were dead. During this interval, comparison of infection by inoculum from alternate host Ribes spp. from this stand, called Champion Mine, with that of presumed wild-type inoculum from elsewhere on western white pine families of known resistant parents led to the conclusion that a new strain of blister rust with wider virulence had arisen (12). Meanwhile, changes in personnel, policy, and program direction occurred. Vanderplank's (19) emphasis on the (theoretical) stability of horizontal resistance, compared with the notorious lability of vertical resistance, dominated strategic thinking, and interest in a possible single gene for resistance that had been suggested by the early data diminished. Results of the early work were never published, and institutional memory of them faded as key personnel departed from the program over the years. 
Our purpose in this paper is to document some of the more important early observations of this program, retrieved from old files as well as from the memory of two of us (G. D. Barnes and T. E. Greathouse) associated with the program in its formative stages. We will then relate these observations to recent experiments designed to test hypotheses suggested by the early data. Specifically, we wished to confirm the inheritance and dominance relationships of a putative major gene for resistance in western white pine; determine its mechanism and mode of expression; and describe its interaction with two known blister rust races of wider virulence than wild type $(10,12)$.

\section{MATERIALS AND METHODS}

Candidate selection. Resistant phenotypes of western white pine were sought in the Cascade Range of Oregon and Washington.

TABLE 1. Rust-free seedlings of western white pine full-sib families from phenotypically selected parents after three artificial inoculations with white pine blister rust, 1959 to 1964

\begin{tabular}{|c|c|c|c|c|c|c|}
\hline \multirow{3}{*}{$\begin{array}{l}\text { Source } \\
\text { (National Forest) }\end{array}$} & & & \multicolumn{4}{|c|}{ Nonsegregating families } \\
\hline & \multicolumn{2}{|c|}{ Parents tested } & \multirow{2}{*}{\multicolumn{2}{|c|}{$\begin{array}{c}\text { Mean no. of } \\
\text { seedlings }\end{array}$}} & \multicolumn{2}{|c|}{ Rust-free (\%) } \\
\hline & Total & Segregating & & & Mean & Range \\
\hline Gifford Pinchot & 15 & 0 & 23 & 80 & 2.2 & $0-12$ \\
\hline Mt. Hood & 9 & 0 & 13 & 62 & 1.4 & $0-6$ \\
\hline Olympic & 7 & 0 & 5 & 30 & 0 & \\
\hline Snoqualamie & 11 & 0 & 16 & 79 & 5.2 & $0-14$ \\
\hline Umpqua $(\mathrm{CM})^{\mathrm{a}}$ & 26 & 22 & 4 & 124 & 11.1 & $3-21$ \\
\hline Willamette (BP) ${ }^{\mathrm{a}}$ & 27 & 10 & 32 & 50 & 1.9 & $0-9$ \\
\hline Total/mean & 95 & 32 & 93 & 70.8 & 3.6 & $0-21$ \\
\hline
\end{tabular}

${ }^{\mathrm{a}} \mathrm{CM}=$ Champion Mine, and $\mathrm{BP}=$ Bear Pass.

TABLE 2. Observed and expected ratios (rust-free/infected) of western white pine full-sib families after three inoculations with white pine blister rust, 1959 to 1964 (Bear Pass group)

\begin{tabular}{|c|c|c|c|c|c|}
\hline \multicolumn{2}{|c|}{ Parents } & \multirow{2}{*}{$\begin{array}{c}\text { No. of } \\
\text { seedlings }\end{array}$} & \multirow{2}{*}{$\begin{array}{c}\% \\
\text { Rust-free }\end{array}$} & \multirow{2}{*}{$\begin{array}{l}\text { Ratio } \\
\text { tested }^{\mathrm{a}}\end{array}$} & \multirow[b]{2}{*}{$P$} \\
\hline Seed & Pollen & & & & \\
\hline 3 & 12 & 28 & 32 & $1: 1$ & 0.057 \\
\hline 4 & 1 & 40 & 58 & $1: 1$ & 0.312 \\
\hline 4 & 33 & 41 & 47 & $1: 1$ & 0.701 \\
\hline 4 & 04-01 & 20 & 40 & $1: 1$ & 0.371 \\
\hline 4 & 04-02 & 67 & 54 & $1: 1$ & 0.513 \\
\hline 9 & 33 & 77 & 44 & $1: 1$ & 0.292 \\
\hline 9 & 36 & 67 & 48 & $1: 1$ & 0.743 \\
\hline 9 & 04-02 & 61 & 54 & $1: 1$ & 0.532 \\
\hline 10 & 04-01 & 21 & 48 & $1: 1$ & 0.855 \\
\hline 10 & 04-02 & 80 & 59 & $1: 1$ & 0.107 \\
\hline 11 & 35 & 25 & 64 & $3: 1$ & 0.204 \\
\hline 14 & 36 & 29 & 45 & $1: 1$ & 0.590 \\
\hline 15 & 35 & 32 & 41 & $1: 1$ & 0.309 \\
\hline 16 & 2 & 28 & 36 & $1: 1$ & 0.138 \\
\hline 18 & 35 & 49 & 47 & $1: 1$ & 0.674 \\
\hline 19 & 32 & 32 & 59 & $1: 1$ & 0.309 \\
\hline 28 & 12 & 21 & 38 & $1: 1$ & 0.271 \\
\hline 32 & 15 & 98 & 51 & $1: 1$ & 0.843 \\
\hline 32 & 18 & 88 & 42 & $1: 1$ & 0.133 \\
\hline 32 & 33 & 94 & 48 & $1: 1$ & 0.698 \\
\hline 32 & 36 & 131 & 44 & $1: 1$ & 0.170 \\
\hline 32 & 04-02 & 95 & 52 & $1: 1$ & 0.697 \\
\hline 35 & 12 & 25 & 92 & $3: 1$ & $0.050^{\mathrm{b}}$ \\
\hline 35 & 15 & 22 & 41 & $1: 1$ & 0.399 \\
\hline 37 & 12 & 31 & 65 & $3: 1$ & 0.199 \\
\hline 37 & 15 & 35 & 34 & $1: 1$ & 0.058 \\
\hline 37 & 18 & 37 & 49 & $1: 1$ & 0.903 \\
\hline 39 & 18 & 31 & 55 & $1: 1$ & 0.578 \\
\hline \multicolumn{6}{|c|}{ Pooled ratios for classes } \\
\hline $3: 1$ & & 81 & 72.8 & $3: 1$ & 0.681 \\
\hline $1: 1$ & & 1,324 & 47.7 & $1: 1$ & 0.114 \\
\hline
\end{tabular}

a Thirty-one nonsegregating families (both parents susceptible) not shown.

b Tested ratio significantly greater than expected at $P=0.05$.
TABLE 3. Observed and expected ratios (rust-free/infected) of western white pine full-sib families after three inoculations with white pine blister rust, 1959 to 1964 (Champion Mine group)

\begin{tabular}{|c|c|c|c|c|c|}
\hline \multicolumn{2}{|c|}{ Parents } & \multirow{2}{*}{$\begin{array}{c}\text { No. of } \\
\text { seedlings }\end{array}$} & \multirow{2}{*}{$\begin{array}{c}\% \\
\text { Rust-free }\end{array}$} & \multirow{2}{*}{$\begin{array}{l}\text { Ratio } \\
\text { tested }\end{array}$} & \multirow[b]{2}{*}{$P$} \\
\hline Seed & Pollen & & & & \\
\hline 801 & 816 & 112 & 72 & $3: 1$ & 0.463 \\
\hline 802 & 820 & 127 & 69 & $3: 1$ & 0.118 \\
\hline 802 & 836 & 69 & 75 & 3:1 & 1.000 \\
\hline 802 & Wind & 80 & 68 & 3:1 & 0.148 \\
\hline 803 & 816 & 94 & 73 & 3:1 & 0.654 \\
\hline 803 & 841 & 119 & 74 & $3: 1$ & 0.801 \\
\hline 806 & 837 & 67 & 76 & $3: 1$ & 0.850 \\
\hline 806 & 840 & 65 & 46 & $1: 1$ & 0.193 \\
\hline 806 & 846 & 92 & 82 & $3: 1$ & 0.121 \\
\hline 813 & 816 & 52 & 72 & $3: 1$ & 0.617 \\
\hline 813 & 836 & 37 & 75 & $3: 1$ & 1.000 \\
\hline 813 & 844 & 51 & 84 & $3: 1$ & 0.138 \\
\hline 814 & 816 & 123 & 81 & $3: 1$ & 0.124 \\
\hline 814 & 820 & 88 & 81 & $3: 1$ & 0.194 \\
\hline 814 & 837 & 36 & 81 & $3: 1$ & 0.406 \\
\hline 814 & 841 & 134 & 81 & $3: 1$ & 0.109 \\
\hline 814 & 872 & 125 & 86 & $3: 1$ & $0.005+\dagger^{\mathrm{a}}$ \\
\hline 816 & 836 & 52 & 67 & $3: 1$ & 0.183 \\
\hline 816 & 837 & 117 & 65 & $3: 1$ & $0.012 * \mathrm{~b}$ \\
\hline 820 & 816 & 134 & 58 & $3: 1$ & $0.000 * * *$ \\
\hline 820 & 836 & 139 & 73 & $3: 1$ & 0.586 \\
\hline 820 & 836 & 102 & 52 & $3: 1$ & $0.000 * * *$ \\
\hline 820 & 837 & 136 & 63 & $3: 1$ & $0.001 * *$ \\
\hline 820 & 841 & 160 & 59 & $3: 1$ & $0.000 * * *$ \\
\hline 834 & 816 & 24 & 92 & $3: 1$ & 0.054 \\
\hline 834 & 816 & 62 & 55 & $3: 1$ & $0.000 * * *$ \\
\hline 834 & 836 & 35 & 86 & 3:1 & 0.133 \\
\hline 834 & 836 & 52 & 58 & $3: 1$ & $0.005^{* *}$ \\
\hline 835 & 836 & 155 & 63 & $1: 1$ & $0.001 * *$ \\
\hline 836 & 836 & 49 & 78 & $3: 1$ & 0.628 \\
\hline 836 & 836 & 108 & 76 & $3: 1$ & 0.810 \\
\hline 836 & 837 & 87 & 67 & $3: 1$ & 0.085 \\
\hline 836 & 841 & 63 & 62 & 3:1 & $0.017 *$ \\
\hline 836 & 846 & 80 & 74 & $3: 1$ & 0.836 \\
\hline 836 & 847 & 122 & 63 & $3: 1$ & $0.002 * *$ \\
\hline 837 & 836 & 63 & 81 & $3: 1$ & 0.271 \\
\hline 837 & 841 & 69 & 64 & 3:1 & $0.035^{*}$ \\
\hline 837 & 844 & 78 & 71 & 3:1 & 0.415 \\
\hline 839 & 836 & 34 & 79 & $3: 1$ & 0.590 \\
\hline 839 & 841 & 52 & 83 & $3: 1$ & 0.183 \\
\hline 840 & 816 & 72 & 6 & $1: 1$ & $0.000 * * *$ \\
\hline 840 & 836 & 82 & 6 & $1: 1$ & $0.000 * * *$ \\
\hline 840 & 837 & 183 & 39 & $1: 1$ & $0.003 * *$ \\
\hline 840 & 837 & 124 & 35 & $1: 1$ & $0.001 * * *$ \\
\hline 840 & 839 & 90 & 50 & $1: 1$ & 1.000 \\
\hline 840 & 840 & 139 & 4 & $?^{\mathrm{c}}$ & \\
\hline 840 & 841 & 134 & 31 & $1: 1$ & $0.000 * * *$ \\
\hline 840 & 844 & 94 & 42 & $1: 1$ & 0.121 \\
\hline 840 & 846 & 93 & 30 & $1: 1$ & $0.000 * * *$ \\
\hline 840 & Wind & 188 & 22 & $?$ & \\
\hline 841 & 816 & 37 & 84 & $3: 1$ & 0.206 \\
\hline 841 & 836 & 109 & 57 & $3: 1$ & $0.000 * * *$ \\
\hline 841 & 837 & 18 & 56 & $3: 1$ & 0.063 \\
\hline 841 & 841 & 91 & 69 & $3: 1$ & 0.186 \\
\hline 841 & 847 & 47 & 83 & $3: 1$ & 0.205 \\
\hline 844 & 836 & 59 & 75 & $3: 1$ & 1.000 \\
\hline 844 & 841 & 136 & 74 & $3: 1$ & 0.788 \\
\hline 844 & 862 & 103 & 66 & $3: 1$ & $0.035^{*}$ \\
\hline 845 & 836 & 83 & 80 & $3: 1$ & 0.293 \\
\hline 845 & 841 & 87 & 66 & $3: 1$ & 0.053 \\
\hline 845 & 844 & 69 & 74 & $3: 1$ & 0.848 \\
\hline 851 & 851 & 140 & 10 & $?$ & \\
\hline 852 & 816 & 30 & 63 & $3: 1$ & 0.129 \\
\hline 852 & 836 & 26 & 88 & $3: 1$ & 0.126 \\
\hline 852 & 841 & 24 & 67 & $3: 1$ & 0.365 \\
\hline 852 & 841 & 80 & 74 & $3: 1$ & 0.836 \\
\hline 854 & 836 & 67 & 82 & $3: 1$ & 0.186 \\
\hline 854 & 841 & 121 & 80 & $3: 1$ & 0.204 \\
\hline 854 & 844 & 106 & 75 & $3: 1$ & 1.000 \\
\hline 863 & 836 & 96 & 57 & $1: 1$ & 0.170 \\
\hline 863 & 837 & 114 & 54 & $1: 1$ & 0.393 \\
\hline 863 & 841 & 99 & 60 & $1: 1$ & $0.047 \dagger$ \\
\hline 871 & 836 & 62 & 87 & $3: 1$ & $0.029 \dagger$ \\
\hline 871 & 841 & 29 & 94 & $3: 1$ & $0.018 \dagger$ \\
\hline 872 & 816 & 149 & 57 & $3: 1$ & $0.000 * * *$ \\
\hline 872 & 820 & 35 & 77 & $3: 1$ & 0.785 \\
\hline 872 & 836 & 110 & 65 & $3: 1$ & $0.015^{*}$ \\
\hline 872 & 841 & 173 & 61 & $3: 1$ & $0.000 * * *$ \\
\hline Pooled & os for $\mathrm{c}$ & & & & \\
\hline $3: 1$ & & 5,075 & 72.7 & $3: 1$ & $0.000 * * *$ \\
\hline $1: 1$ & & 1,401 & 39.9 & $1: 1$ & $0.000 * * *$ \\
\hline
\end{tabular}

$\mathrm{a} \dagger, \dagger \dagger=$ Tested ratio significantly greater than expected at $P=0.05$ and 0.01 , respectively. $\mathrm{b} *, * *, * * *=$ Tested ratio significantly less than expected at $P=0.05,0.01$, and 0.001 , respectively.

c ? = Ratio unknown. 
Criteria for selection were sexual maturity and absence of blister rust infection in stands where heavy infection was pervasive. Candidates were controlled pollinated in the wild, using highly fecund trees to test several other pollen parents in each selection unit. A total of 95 parents was selected and bred in the wild in six National Forests (NF), and 136 full-sib families were produced by 1964 (Table 1). Many crosses were later made on ramets of the same parents in a grafted seed orchard.

Two stands in the Western Cascades of Oregon that yielded families segregating for resistance were Bear Pass (BP), in the Willamette NF, and Champion Mine (CM), in the Umpqua NF. The BP stand was an old plantation, established in 1916 and at least partially reestablished in 1936 after much of the original stand failed. Stand establishment records are incomplete, and we have been unable to positively determine the seed origin of the plantation. The CM site was named after a gold mine that operated intermittently from 1896 to 1941 . Situated in a narrow, steep canyon drained by Champion Creek, its topography and north-facing aspect make it an unusually cool and moist site for the area, an ideal habitat for blister rust and, therefore, for phenotypic selection. The parent trees selected on this site, starting in 1957, were second growth, dating from about 1920. The area of western white pine regeneration was only about 100 acres, between an elevation of 4,200 and 4,800 feet. A few scattered old-growth western white pines still survive on the ridge tops, but the site is otherwise isolated from other western white pine stands, and the trees at CM may have represented a relatively narrow genetic base.

Progeny testing: Early inoculations (1959 to 1964). Usually, 100 seed were sown for each full-sib family, and seedlings were grown in metal one-gallon pots, one seedling to a pot, initially at a U.S. Forest Service nursery at Wind River, OR, and then at a work center at Layng Creek near Cottage Grove, OR. After their second growing season, seedlings were moved into an open-faced equipment storage shed in the autumn for inoculation and arranged in a quasi-random manner. The face of the shed was covered with canvas and the canvas, floor, and walls saturated with water, as well as the seedling potting soil. Whole branches of different Ribes spp. (mainly $R$. bracteosum Douglas and $R$. sanguineum Pursh, but occasionally including $R$. roezlii Regel var. cruentum Greene (Rehd.) and $R$. lacustre Pers. (Poir)) with heavily rust-infected leaves were stuck into the pots, where they remained for 3 days under highly humid conditions. The inoculum was obtained from various NF sites in the region, which almost always included CM (Umpqua NF) and Still Creek (Mt. Hood NF) because of their abundant and dependable yields. Telia were monitored for germination, and water droplets on needles were sampled and examined microscopically for presence of basidiospores, but inoculum density was not quantified. Each family was inoculated in this manner in 3 successive years.

Foliage symptoms were noted, but no attempt was made to quantify amounts of infection or to distinguish between different needle spot phenotypes. Seedlings were scored only for presence or absence of stem infection 1 year after each inoculation.

Progeny testing: 1996 to 1997 inoculations. Seed from many of the same or similar families in the early tests were cold-stratified for 120 days and sown into Leach Super cells $\left(164 \mathrm{~cm}^{3}\right.$; Ray Leach Nursery, Canby, OR) in racks, 98 per rack, in early March. In the 1996 test, seedlings were grown with the photoperiod ex-
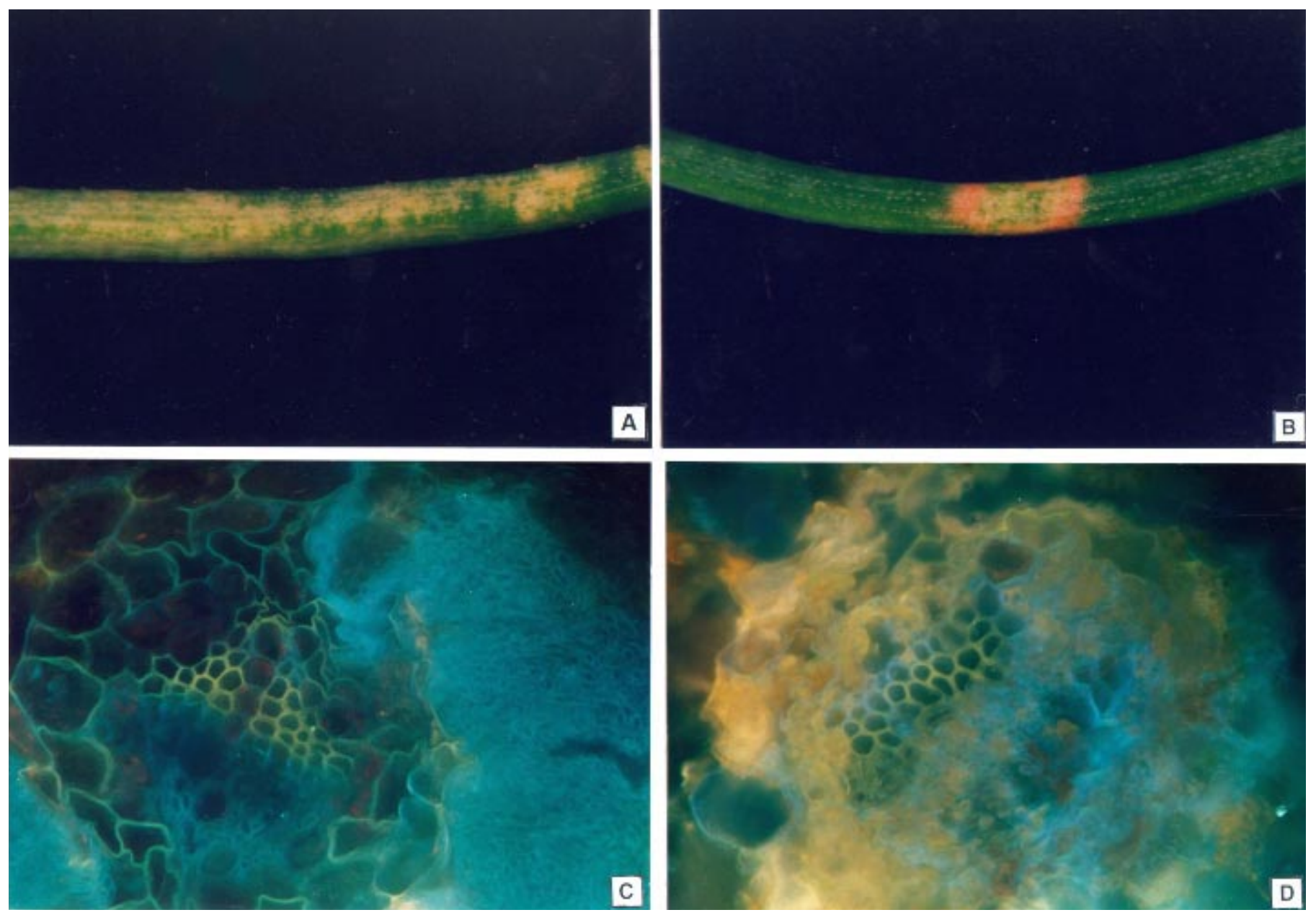

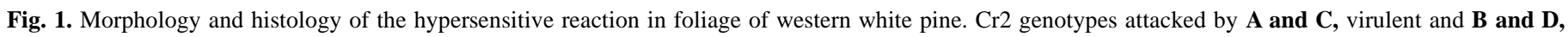

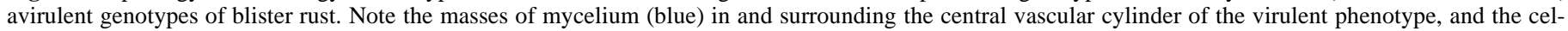
lular disorganization, necrosis, and lack of viable mycelium in the avirulent phenotype. B and D, Fluorescent illumination. 
tended to 16 -h days by $400-\mathrm{W}$ high-pressure sodium lamps and with weekly, dilute fertilization to promote growth and early secondary needle production. They were inoculated in September, after most had formed secondary needles but still had viable cotyledons and primary needles. Seedlings in the 1997 test were inoculated only 6 weeks after sowing, while still in the cotyledon and early primary needle stage.

Inoculum for the 1996 test included sources from CM and vicinity, including the Layng Creek Ribes garden (used as a source of inoculum for annual screening tests) and Bryce Creek, $2 \mathrm{~km}$ downslope from CM. CM and Layng Creek were sources known or thought to have factors for wider virulence than wild type (12). Inoculum was also sampled from the U.S. Forest Service test site near Happy Camp, source of the race of rust virulent to major gene resistance in sugar pine, in the Siskyou mountains of northern California (10). Pooled inoculum from several sites in El Dorado County, CA, remote from sites known to harbor wider virulence, was chosen, based on previous experience, to represent wild-type inoculum. At each site, Ribes leaves with mature telia were collected from many different bushes, mixed, and refrigerated in polyethylene bags until used, usually within 3 days. All sources of inoculum were kept and used separately. Thus, inoculum was homogenized for each source, but variation in virulence among individual basidiospores within a source, if any, could be detected by differences in needle spot phenotypes on test seedlings with a resistance gene. Seedlings in the 1997 test were inoculated with wild type only.

Seedlings were incubated at $15 \pm 0.6^{\circ} \mathrm{C}$ for $48 \mathrm{~h}$ in darkness in dew chambers (model I-35D; Percival Manufacturing Co., Boone, IA) with detached Ribes leaves suspended over the seedlings on wire frames. Our objective was to induce heavy basidiospore production in order to minimize escapes and to enhance the unambiguous expression of any qualitative phenotypic differences in needle symptoms. Inoculum density was quantified by counts of spores cast onto microscope slides placed horizontally at seedling height, two per rack (one per square foot), sampled through an ocular grid. Fine dewdrops condensed on seedling foliage, without runoff. At the end of incubation, dew chamber doors were opened and seedlings allowed to dry gradually for the next $24 \mathrm{~h}$, before being returned to greenhouse benches.

\section{RESULTS}

1959 to 1964 inoculations. Overall results of the early tests are given in Table 1. Although needle symptoms were observed, only presence or absence of stem symptoms were recorded, 1 year after each of the three inoculations. Thirty-two parents had families with very high proportions of rust-free seedlings after the third inspection, with modal points around 50 and $75 \%$. These were interpreted as segregating for a major gene for resistance (Tables 2 and 3). Parents with this gene came from only two sources: the BP stand in the Willamette NF (10 parents), and the CM stand in the Umpqua NF (22 parents). Parents from the other four NFs had few or no rustfree offspring. The mean percentage of rust-free seedlings for 93 nonsegregating, full-sib families from all forests was only $3.6 \%$, although a few families ranged considerably higher than this, from about 10 to $21 \%$ (Table 1 ).

Parent genotypes were inferred from progeny performance. Most parents with the dominant gene appeared to be heterozygotes; no families with nonsegregating rust-free offspring were found. Chisquare tests for conformance to hypothesized Mendelian segregation ratios (1:1 and 3:1, representing parental genotypes $\mathrm{Rr} \times \mathrm{rr}$ and $\mathrm{Rr} \times \mathrm{Rr}$, respectively) are given in Tables 2 and 3 for BP (Willamette NF) and CM (Umpqua NF) parent groups, respectively.

We designate this locus $\mathrm{Cr} 2$, following suggested nomenclature for resistance gene loci (22), to distinguish it from a similar gene in sugar pine, $\mathrm{Cr} 1$ (formerly $\mathrm{R})(8,11)$.

$B P$ group. In this group, 10 of 26 parent trees were inferred to be heterozygous at $\mathrm{Cr} 2$, based on Mendelian segregation ratios of their progenies. Of 28 segregating families, 25 segregated in 1:1 and 3 in 3:1 ratios (Table 2). None of the observed ratios was significantly different from those expected, although four approached significance with probabilities ranging from 0.05 to 0.10 . Pooled ratios for the two classes (1:1 and 3:1) were also nonsignificant. An anomalous progeny $(16 \times 2)$ appeared to segregate in a $1: 1$ ratio when no other families of either of these parents did.

CM group. The CM group contrasted strongly to the BP group in two ways. First, many more parents (22 of the 26) appeared to be segregating at $\mathrm{Cr} 2$ in almost all of their crosses (Table 3). Parent 835 , appearing in only one cross with a heterozygote, was ambiguous, as was to some extent parent 863 , appearing in three crosses

TABLE 4. Percentages and expected ratios of western white pine full-sib families expressing a hypersensitive reaction (HR) in cotyledons after challenge with white pine blister rust and percentage of HR seedlings developing stem symptoms from different inoculum sources, 1996

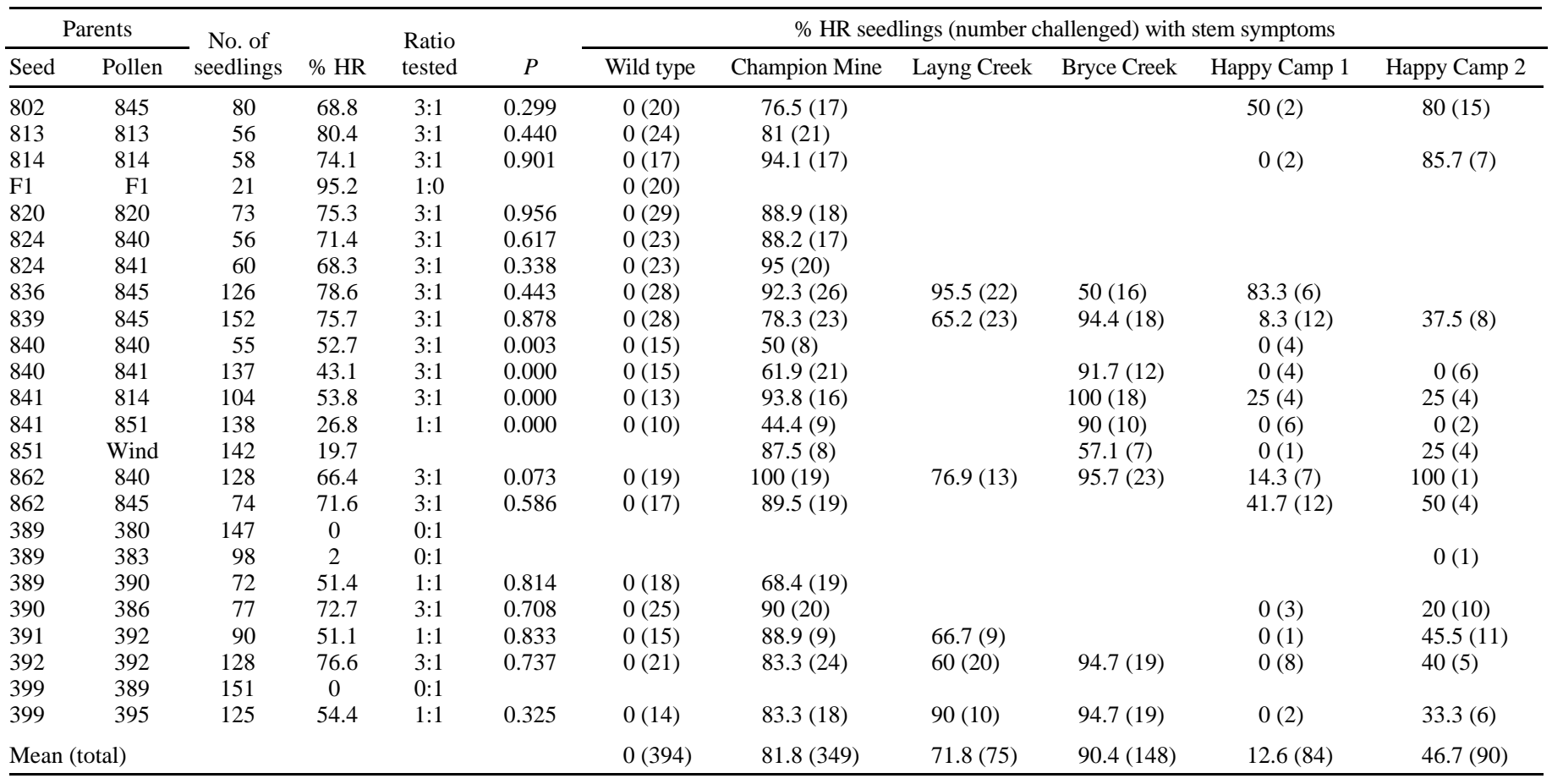


with other heterozygotes. In these early tests, only parents 840 , in 11 crosses, and 851, in a single selfed cross, appeared to lack the dominant allele.

Secondly, many more progenies of heterozygous parents had skewed ratios. Of the 76 families, 26 departed significantly from ratios expected and tested by chi-square. Most ( 22 families) had significantly fewer numbers of rust-free seedlings than expected, while only four had greater-than-expected numbers of rust-free seedlings. Pooled ratios for classes (1:1 and 3:1) were highly significant.

Almost half of the parents produced families with skewed ratios, but three parents stood out, especially as seed parents: 820 (four out of five families), 840 (six out of nine families), and 872 (three out of four families). As pollen parents, 820 performed as expected in three crosses and 840 in one cross, while 872 had significantly higher numbers of rust-free seedlings in one cross. Parent 840 was the most conspicuous deviant; in crosses with confirmed $\mathrm{Cr} 2 \mathrm{cr} 2$ pollen parents 816 and 836, it suppressed expression of $\mathrm{Cr} 2$ almost completely-6\% rust-free seedlings in each (versus $50 \%$ expected). With pollen parents 837,841 , and 846 , proportions of rust-free seedlings were only partially reduced. On the other hand, a few trees such as 836 and 841 had more deviant families as pollen parents.

1996 to 1997 inoculations. All seedlings in the 1996 sowing had healthy cotyledons and primary needles at the time of inoculation (autumn), and most also bore secondary needles. Inoculum density averaged 99.6 basidiospores per $\mathrm{mm}^{2}$, and infection was moderate to heavy with all inocula except Happy Camp, which only cast six spores per $\mathrm{mm}^{2}$ with correspondingly lighter infection. Reinoculation of escapes in July 1997 with this source, however, resulted in heavy infection.

Needle symptoms started to appear about 2 weeks after inoculation. There were two main types: typical yellow (occasionally red) spots on known susceptible control seedlings (Fig. 1A) and brown necrotic spots on seedlings with $\mathrm{Cr} 2$, a classic hypersensitive reaction (HR) (Fig. 1B). Yellow or red spots were also induced on $\mathrm{Cr} 2$ - genotypes by virulent inoculum. HR symptoms were indistinguishable from susceptible symptoms in very early stages, until a thin, barely visible, necrotic band appeared at the margins of the spots. Necrosis then spread inward until the entire spot was brown. Symptoms were the same on all foliar types, but the earliest and most definitive expression was on cotyledons.

Histological examination of HR showed characteristic cellular degeneration of both host and fungal cells (Fig. 1D), similar to HR in sugar pine (6), while yellow spots (susceptible reactions) had masses of viable and vigorous mycelium (Fig. 1C).

The two phenotypic classes assigned for analysis of Mendelian segregation were presence or absence of HR. Seedlings with mixed reactions were designated $\mathrm{HR}$, because $\mathrm{HR}$ only occurs on $\mathrm{Cr} 2-$ genotypes. There were no differences among inocula in the segregation ratios of different full-sib families, and needle symptom data were pooled over all inoculum sources (Table 4). Segregation ratios (3:1 and 1:1) for presence/absence of HR were virtually identical to those for rust-free/rust-infected in the earlier inoculations involving many of the same parents (cf. Table 3), based on stem infection only, demonstrating that HR was the mechanism of resistance to stem infection. The single family from a cross of two F1 offspring from different heterozygous parents was $95 \% \mathrm{HR}$, indicating that at least one of the F1 parents is probably homozygous $(\mathrm{Cr} 2 \mathrm{Cr} 2)$. Four families, however, deviated significantly from ratios expected under the dominant gene hypothesis. These were among the same parents and families that had significant deviations in the early tests, namely $814,820,840$, and 841 (cf. Table 3).

In contrast to the clear segregation of needle spot phenotypes, development of stem infection differed greatly among the inocula. Wild-type inoculum was the only source completely avirulent to $\mathrm{Cr} 2$, inducing only HR lesions on Cr2- genotypes (Table 4). No seedlings with HR subsequently got stem infections from wild-type inoculum, but most seedlings (72 to 90\%) (Table 4) with HR did get stem infections from inocula from $\mathrm{CM}$ and the three neighboring sites (Bryce Creek, Grass Creek, and Layng Creek). All inocula except wild type also induced some yellow (susceptible) needle symptoms on seedlings with predominantly HR symptoms, implying the presence of virulent rust genotypes in these inocula at low frequencies. None of the inocula were completely virulent. Accurate counts for comparison of relative frequencies of the two spot classes on individual seedlings was not possible, because infection was heavy and yellow spots coalesced too rapidly. Happy Camp inoculum had the lowest incidence of seedlings with stem infections in both inoculations with this source (13 and 47\%) and also induced the fewest yellow spots.

The 1997 inoculation included as many families as available of parents that showed skewed ratios in either the early tests or the 1996 test. Emphasis was on families of 814, 820, 840, and 841, all in the CM group, both as seed or pollen parents. Inoculation was with wild type only. All but 2 of the 30 families performed as expected, based on previous results (Table 5). One of these, $841 \times 813$, segregated in a ratio of 1:1 versus the 3:1 ratio expected from other crosses involving these parents in this and the earlier tests. In the other, $840 \times 846$, the HR was almost completely suppressed: only a single seedling showed this trait, when 30 (out of 40) were expected to. But as pollen parent in four crosses (with seed parents $803,813,817$, and 823, all heterozygous at $\mathrm{Cr} 2$ ), 840 also performed as a $\mathrm{Cr} 2$ heterozygote (as it did with seed parent 824 in the 1996 inoculation) (Table 4).

Combining data from Tables 3 to 5 shows that a quarter (32 of 120) of the segregating families in the CM group had fewer than expected offspring expressing $\mathrm{Cr} 2$ (compared with 0 of 28 families for BP) (Table 2). These were distributed among many of the parents, but over half derived from parents 820, 840, and 872,

TABLE 5. Percentages and expected ratios of western white pine full-sib families expressing a hypersensitive reaction (HR) in cotyledons after challenge with wild-type inoculum, 1997

\begin{tabular}{|c|c|c|c|c|c|}
\hline \multicolumn{2}{|c|}{ Parents } & \multirow{2}{*}{$\begin{array}{c}\text { No. of } \\
\text { seedlings }\end{array}$} & \multirow[b]{2}{*}{$\% \mathrm{HR}$} & \multirow{2}{*}{$\begin{array}{l}\text { Ratio } \\
\text { tested }\end{array}$} & \multirow[b]{2}{*}{$P$} \\
\hline Seed & Pollen & & & & \\
\hline 802 & 845 & 35 & 77.1 & $3: 1$ & 0.770 \\
\hline 803 & 840 & 52 & 88.5 & $3: 1$ & $0.025 \dagger^{\mathrm{a}}$ \\
\hline 813 & 840 & 46 & 82.6 & $3: 1$ & 0.233 \\
\hline 814 & 852 & 36 & 66.7 & $3: 1$ & 0.248 \\
\hline 814 & 862 & 40 & 65 & $3: 1$ & 0.144 \\
\hline 814 & 867 & 40 & 77.5 & $3: 1$ & 0.715 \\
\hline 814 & 869 & 40 & 77.5 & $3: 1$ & 0.715 \\
\hline 817 & 840 & 40 & 75 & $3: 1$ & 1.000 \\
\hline 819 & 845 & 44 & 72.7 & $3: 1$ & 0.728 \\
\hline 820 & 820 & 28 & 67.9 & $3: 1$ & 0.383 \\
\hline 820 & 510 & 14 & 78.6 & $3: 1$ & 0.758 \\
\hline 823 & 840 & 40 & 77.5 & $3: 1$ & 0.715 \\
\hline 824 & 845 & 40 & 67.5 & $3: 1$ & 0.273 \\
\hline 836 & 845 & 28 & 75 & $3: 1$ & 1.000 \\
\hline 839 & 845 & 40 & 75 & $3: 1$ & 1.000 \\
\hline 840 & 846 & 40 & 2.5 & $3: 1$ & $0.000 * * * \mathrm{~b}$ \\
\hline 841 & 841 & 32 & 84.4 & $3: 1$ & 0.221 \\
\hline 841 & 813 & 31 & 48.4 & $3: 1$ & $0.001 * * *$ \\
\hline 841 & 814 & 40 & 80 & $3: 1$ & 0.465 \\
\hline 841 & 851 & 51 & 41.2 & $1: 1$ & 0.208 \\
\hline 841 & 852 & 39 & 66.7 & $3: 1$ & 0.229 \\
\hline 841 & 862 & 40 & 80 & $3: 1$ & 0.465 \\
\hline 841 & 867 & 35 & 65.7 & $3: 1$ & 0.205 \\
\hline 841 & 869 & 40 & 72.5 & $3: 1$ & 0.715 \\
\hline 854 & 820 & 40 & 72.5 & $3: 1$ & 0.715 \\
\hline 868 & 820 & 40 & 82.5 & $3: 1$ & 0.273 \\
\hline 870 & 820 & 40 & 77.5 & $3: 1$ & 0.715 \\
\hline 876 & 820 & 39 & 84.6 & $3: 1$ & 0.166 \\
\hline 896 & 820 & 39 & 74.4 & $3: 1$ & 0.926 \\
\hline 389 & 383 & 38 & 0.0 & $0: 1$ & \\
\hline \multicolumn{4}{|c|}{ Pooled test } & $3: 1$ & $0.036^{*}$ \\
\hline \multicolumn{4}{|c|}{ Pooled test, excluding $840 \times 846$} & $3: 1$ & 0.718 \\
\hline
\end{tabular}

$\mathrm{a} \dagger=$ Tested ratio significantly greater than expected at $P=0.05$.

b $*, * * *=$ Tested ratio significantly less than expected at $P=0.05$ and 0.001 , respectively. 
mainly as seed parents. For example, deficient numbers of offspring expressing $\mathrm{Cr} 2$ occurred in four of eight families of 820 as seed parent, but in none of the 10 families of the same tree as pollen parent. The corresponding figures for 840 were 12 out of 12 as seed parent, but only three out of nine as pollen parent (only one of seven, if two selfed families are excluded). Only five families expressed greater-than-expected numbers of resistant seedlings.

Sixteen families were represented in two different inoculation years. In at least six of these comparisons, results were inconsistent between years $(820 \times 836,834 \times 816$, and $834 \times 836$ [Table 3]; $840 \times 840$ [Tables 3 and 4]; $840 \times 846$ [Tables 3 and 5]; and $841 \times$ 814 [Tables 4 and 5]).

\section{DISCUSSION}

Evidence from all the test inoculations leads consistently to three main conclusions: (i) a dominant gene controlling classical HR to white pine blister rust exists in some natural populations of western white pine; but (ii) penetrance of this gene can be strongly affected by the genetic background, resulting in altered Mendelian ratios; and (iii) the $\mathrm{CM}$ race of rust capable of neutralizing this gene exists in some blister rust populations at low but varying frequencies.

Mendelian segregation patterns for HR in foliage in the 1996 to 1997 inoculations were identical to those for rust-free stems in the 1959 to 1964 inoculations (Tables 3 to 5), and no seedlings challenged with wild-type inoculum that had HR symptoms subsequently developed stem symptoms. The HR in western white pine is similar to the HR in many other plant pathosystems and, in particular, to the HR conditioned by major gene resistance in sugar pine foliage (6). Since similar disease reaction phenotypes can be controlled by different genes, this does not necessarily imply that the two genes identified are the same in the two pine species. However, we have recent evidence (data not shown) that CM and $\mathrm{CM}$-related inoculum does not neutralize $\mathrm{Cr} 1$ in sugar pine, suggesting that genetic specificity exists among resistance and virulence loci in this pathosystem. Nor do our data prove that $\mathrm{Cr} 2$ is the only major gene locus for resistance in these western white pine populations or even identical in all of the genotypes tested; formal proof would require precise genetic control of test inoculum rather than the bulk mixes we used.

Penetrance of $\mathrm{Cr} 2$ ranged from complete to almost nil, depending on the specific combination of parents in the cross. This was most evident in the CM group. About a third of the families showed altered ratios (mostly fewer-than-expected numbers of rust-free or HR seedlings), but some parents influenced this tendency to a much greater extent than others. Parent 840 was the most conspicuous example, particularly as a seed parent, in which all of its 12 families showed suppression of $\mathrm{Cr} 2$, ranging from moderate to nearly complete. As seed parent, 840 often suppressed both its own $\mathrm{Cr} 2$ allele as well as that of other heterozygote pollen parents (e.g., 816, 836, self, and 846) (Tables 3 to 5), although duplicate trials of the same crosses were inconsistent in two cases (selfed and with 846). As a pollen parent, however, 840 performed like a normal heterozygote in all but one case (with seed parent 806) (Table 3). Parents 820 and 872 had similar patterns, if less pronounced in effect. The significance of these apparent maternal effects on a demonstrably nuclear gene are difficult to evaluate from these data, but it is clear that expression of $\mathrm{Cr} 2$ is profoundly affected by modifying genes in certain genetic backgrounds.

Although the influence of genetic background on the expression of disease phenotype has long been recognized in a general way, recent emphasis has focused on suppressors and modifiers with major effects on $\mathrm{R}$ genes. Examples include a dominant suppressor specific to the Pm8 allele for resistance to powdery mildew in wheat (18); another locus in wheat that suppresses up to three $\mathrm{R}$ genes for stem rust resistance (21); three suppressors in barley that differentially affect some specific powdery mildew $\mathrm{R}$ genes but not others (7); and in Arabidopsis, the suppression by a mutated R gene against one pathogen of $\mathrm{R}$ genes that function against different pathogens (20). The literature was reviewed by Jorgensen (7), who noted that differential effects of suppressors on different $\mathrm{R}$ genes imply that these $\mathrm{R}$ genes employ or involve different cascade pathways in defense. Thus, suppression or modification of expression can occur either to regulatory genes or to structural genes downstream in the cascade. This provides a heuristic rationalization of both the qualitative and quantitative effects of the $\mathrm{R}$ gene modification we document here.

Altered Mendelian ratios could also be explained by pollen contamination. While pollen contamination cannot be disproved in any given cross, we consider it an unlikely cause of the large numbers of discrepancies observed. First, significantly altered ratios occurred only in the CM group in the early tests, even though matings of both $\mathrm{CM}$ and BP groups were made by the same personnel during the same period of time. Secondly, repeat trials of some of the same CM parents (e.g., 840 and 841) in the 1996 to 1997 inoculations produced similar results as with the earlier inoculations (cf. Tables 4 and 5 with Table 3).

Virulence to $\mathrm{Cr} 2$ is clearly present in some rust populations, most notably at CM (where we expected to find it) (12) and neighboring sites. Virulence was indicated in these inocula by presence of susceptible (yellow)-type needle spots in low frequency on $\mathrm{Cr} 2$ - seedlings (seedlings with mostly HR reactions) and by the subsequent development of stem symptoms and signs on a high proportion of these seedlings (Table 4). In contrast, no trace of virulent needle spot phenotypes was observed from inoculum from the El Dorado, CA, site, which we chose to represent typical wild type, and no HR phenotypes induced by this inoculum developed stem symptoms.

Although incidence of stem infection on Cr2- genotypes from $\mathrm{CM}$ and near-neighbor inocula was high, the actual frequency of yellow spots (the phenotypic marker of virulence) on the same seedlings was low. Precise counts of virulent and avirulent spot phenotypes were not possible, but we estimate that the frequency of virulence was less than $3 \%$. This was still more than enough to cause a high incidence of stem infection, however, since a single compatible needle infection can cause stem infection. The stem infection that did result provides a ready explanation for the apparent erosion of resistance observed in annual screening tests after the appearance of the CM strain in the late 1960s. Virulence was also evident in inoculum from Happy Camp, about 110 miles southwest of CM, though at a lower frequency than CM and neighboring inocula. We do not know whether this represents a spontaneous separate occurrence or migration from CM.

In the initial characterization of the $\mathrm{CM}$ strain (12), resistant western white pines were used to compare the effects of $\mathrm{CM}$ and wild-type inocula. Parent genotypes and their resistance mechanisms were not described, but records at the U.S. Forest Service Dorena Tree Genetic Resource Center show that all parents used in the referenced test were from the CM population. Several symptom traits induced by $\mathrm{CM}$ inoculum were described that appeared to differ quantitatively from the other inocula used. Our data suggest, more simply, that a specific resistance gene in the host is neutralized by a corresponding gene for virulence in the rust, very similar to the situation in sugar pine (10) and in gene-for-gene systems in general.

The existence of rust-free seedlings at low frequency $(3.6 \%)$ (Table 1) in nonsegregating families in almost all seed sources used in the early (1959 to 1964) inoculations is evidence that other strong resistance mechanisms may exist in western white pine. Because all families were inoculated three times in successive years, the challenge was severe and the probability of escape was low. Although we did not observe similar low-level resistance in the 1996 to 1997 inoculations, these involved a narrower population base composed almost entirely of CM parents.

Absence of $\mathrm{Cr} 2$ in any seed sources other than $\mathrm{BP}$ and $\mathrm{CM}$ is curious and might be explained by a combination of the low fre- 
quency of this allele and the relatively fewer parents tested in the other sources. The frequency of $\mathrm{Cr} 2$ in the original, unchallenged pine populations at $\mathrm{BP}$ and $\mathrm{CM}$ cannot be estimated from these data, but must have been low even at CM, since none of the 22 parents with this allele was homozygous. The difference in the frequency of $\mathrm{Cr} 2$ - genotypes between the $\mathrm{CM}$ and $\mathrm{BP}$ groups is more problematic and adds to the frustration of our uncertainty about the seed origin of BP. We do know that natural selection against susceptible genotypes in both populations was intense; the CM site, in particular, was known to lie in an area of severe rust hazard long before 1957, when selections for resistant phenotypes were begun there. The completely susceptible families produced by heavily challenged, resistant phenotypes at BP could be explained by ontogenetic resistance, a type of resistance that develops with age and is known in other white pines $(9,16)$. However, there was little evidence for this mechanism at $\mathrm{CM}$.

Equally curious is the apparent absence of $\mathrm{Cr} 2$ in northern Rocky Mountain populations, where selection and breeding for blister rust resistance has been ongoing since 1950 (2). Reactions similar to HR have been documented but attributed to recessive genes at two different loci $(6,13,14)$. Clearly, a comprehensive screening involving all major populations of $P$. monticola is needed to accurately resolve the distribution and frequency of $\mathrm{Cr} 2$.

Like all HR genes, $\mathrm{Cr} 2$ is very strong, yet completely vulnerable to a gene in the pathogen with specific virulence to it, as the complete extirpation of the CM parent population over little more than 2 decades clearly indicates. Its value in protecting synthetic populations of western white pines being developed in breeding programs in western North America will depend somewhat on the distribution, frequency, and potential migration rate of the presumed virulence gene in the $\mathrm{CM}$ and like populations of rust. Standing alone, the durability of $\mathrm{Cr} 2$ will probably be relatively short-lived. But buffered with rate-reducing and other resistance mechanisms, it could be extremely effective.

\section{ACKNOWLEDGMENTS}

We thank A. Delfino-Mix and G. Dupper for implementing the 1996 to 1997 experiments at the Institute of Forest Genetics, and D. B. Neale, A. Yanchuck, and two anonymous reviewers for constructive suggestions of earlier drafts.

\section{LITERATURE CITED}

1. Benedict, W. V. 1981. History of White Pine Blister Rust Control-A Personal Account. U.S. Dep. Agric. For. Serv. FS-355.

2. Bingham, R. T. 1983. Blister rust resistant western white pine for the inland empire: The story of the first 25 years of the research and development program. U.S. Dep. Agric. For. Serv. Gen. Tech. Rep. INT-146. Intermountain Forest and Range Experiment Station, Ogden, UT.
3. Bingham, R. T., Olson, R. J., Becker, W. A., and Marsden, M. A. 1969. Breeding blister rust resistant white pine. V. Estimates of heritability, combining ability, and genetic advance based on tester matings. Silvae Genet. 18:23-38.

4. Graham, R. T. 1990. Pinus monticola Dougl. ex D. Don. western white pine. Pages 385-394 in: Silvics of North America. Vol. 1: Conifers. R. M. Burns and B. H. Honkala, technical coordinators. Agric. Handb. 654. Washington, DC.

5. Harrington, T. C., and Wingfield, M. J. 1998. Diseases and the ecology of indigenous and exotic pines. Pages 381-404 in: Ecology and Biogeography of Pinus. D. M. Richardson, ed. Cambridge University Press, Cambridge.

6. Hoff, R. J., and McDonald, G. I. 1971. Resistance of Pinus monticola to Cronartium ribicola: Short shoot fungicidal reaction. Can. J. Bot. 49: 1235-1239.

7. Jorgensen, J. H. 1996. Effect of three suppressors on the expression of powdery mildew resistance genes in barley. Genome 39:492-498.

8. Kinloch, Jr., B. B. 1992. Distribution and frequency of a gene for resistance to white pine blister rust in natural populations of sugar pine. Can. J. Bot. 70:1319-1323.

9. Kinloch, Jr., B. B., and Byler, J. W. 1981. Relative effectiveness and stability of different resistance mechanisms to white pine blister rust in sugar pine. Phytopathology 71:386-391.

10. Kinloch, B. B., and Comstock, M. 1981. Race of Cronartium ribicola virulent to major gene resistance in sugar pine. Plant Dis. 65:604-605.

11. Kinloch, Jr., B. B., and Littlefield, J. L. 1977. White pine blister rust: Hypersensitive resistance in sugar pine. Can. J. Bot. 55:1148-1155.

12. McDonald, G. I., Hansen, E. M., Osterhaus, C. A., and Samman, S. 1984. Initial characterization of a new strain of Cronartium ribicola from the Cascade Mountains of Oregon. Plant Dis. 68:800-804.

13. McDonald, G. I., and Hoff, R. J. 1970. Resistance of Pinus monticola to Cronartium ribicola: Early shedding of infected needles. U.S. Dep. Agric. For. Serv. Res. Note INT-124. Intermountain Forest and Range Experiment Station, Ogden, UT.

14. McDonald, G. I., and Hoff, R. J. 1971. Resistance of Pinus monticola to Cronartium ribicola: Genetic control of needle-spots-only resistance factors. Can. J. For. Res. 1:197-202.

15. Monnig, E., and Byler, J. 1992. Forest Health and Ecological Integrity in the Northern Rockies. U.S. Dep. Agric. For. Serv. FPM Rep. 92-7.

16. Patton, R. F. 1961. The effect of age upon susceptibility of eastern white pine to infection by Cronartium ribicola. Phytopathology 51:429-434.

17. Peterson, R. S., and Jewell, F. F. 1968. Status of North American pine stem rusts. Annu. Rev. Phytopathol. 6:23-40.

18. Ren, S. X., McIntosh, R. A., Sharp, P. J., and The, T. T. 1996. A storageprotein marker associated with the suppressor of Pm8 for powdery mildew resistance in wheat. Theor. Appl. Genet. 93:1054-1060.

19. Vanderplank, J. E. 1963. Plant Diseases: Epidemics and Control. Academic Press, New York.

20. Warren, R. F., Henk, A., Mowery, P., Holub, E., and Innes, R. W. 1998. A mutation within the leucine-rich repeat domain of the Arabidopsis disease resistance gene RPS5 partially suppresses multiple bacterial and downy mildew resistance genes. Plant Cell 10:1439-1452.

21. Williams, N. D., Miller, J. D., and Klindworth, D. L. 1992. Induced mutations of a genetic suppressor of resistance to wheat stem rust. Crop Sci. 32:612-616.

22. Yoder, O. C., Valent, B., and Chumley, F. 1986. Genetic nomenclature and practice for plant pathogenic fungi. Phytopathology 76:383-385. 